\title{
A Comparison Study for the Thermal and Physical Properties between "Al-Mangabi" and the Available Building Materials for the External Walls in Jeddah
}

\author{
Mohammed Bagader ${ }^{1}$ and Mady Mohamed M $^{2}$ \\ ${ }^{1}$ Islamic Architecture Department, College of Engineering and Islamic Architecture/ Umm Al-Qura University, Saudi Arabia. \\ ${ }^{2}$ Architecture Department, College of Architecture and Design / Effat University, Saudi Arabia. \\ ${ }^{3}$ Architecture Department, College of Engineering, Zagazig University, Egypt. \\ ORCID: 0000-0002-1189-3639 (Mohammed Bagader), ORCID: 0000-0001-6831-176X (Mady Mohamed)
}

\begin{abstract}
Vernacular building techniques and materials have been abandoned worldwide and particularly in the hot humid region. These techniques and materials stand for a long time and proved its efficiency in dealing with the climate. Al-Bald district in Jeddah City in Saudi Arabia is no exception. Al-Mangabi (coral stone) stone is dominated by traditional materials that have been used to construct the vernacular Jeddah's buildings, which are still standing in Historic Jeddah as great evidence of the efficiency of this material. Al-Mangabi stone is available all over the city of Jeddah usually it brought form the sea reefs directly with some traditional drought techniques. Using building materials with high thermal mass in a hot arid climate can save too much energy in cooling down the buildings. This paper analyzes the characteristics of AlMangabi stone as a construction and high thermal mass material. This is achieved through reviewing the history of using this material in Jeddah and comparing Al-Mangabi stone with the commonly available building materials used in buildings in Jeddah. Physical and numerical experiments are conducted in order to quantify the thermal effectiveness of AlMangabi stone. Results revealed the high thermal efficiency of Al-Mangabi stone is very close to a cavity wall with insulation and hence it can promote its role to be a very efficient building materials for external walls while it could be used as a cladding material to provide aesthetic features with insulation function in Jeddah's market.
\end{abstract}

Keywords - Al-Mangabi stone, Historic Jeddah, insulation, vernacular materials, thermal mass

\section{INTRODUCTION}

In the past few decades, thermal building insulation materials and solutions have become fundamentals for building envelops due to their important roles in the energy conservation and users' thermal comfort within spaces [1]. In addition, a huge amount of the world's total energy use and greenhouse gas emissions have been results of the building sector. Therefore, Jelle [2] claims that an urgent demand to improve energy efficiency in buildings was needed. He also argues that the main key factor of a thermal building insulation material...[2]. $\mathrm{He}$ also argues that the main key factor of a thermal building insulation material or solution is the thermal conductivity, and many countries launched a national strategy to achieve low thermal conductivity values $(\mathrm{W} /(\mathrm{mK}))$ as much as possible.

In order to achieve the most conceivable thermal insulation resistance, new insulation materials and solutions with low thermal conductivity values have been developed but they can harm the environment and relatively expensive [3]. However, old traditional materials (such as coral stones, masonry, and more) have significant low thermal conductivity values that can be developed to achieve the desired thermal insulation values without harming the environment and they are available in reasonable quantities.

The authors claim that Al-Mangabi stone is a traditional/natural material used to be Jeddah's main construction and insulation material that can be developed to cope with today's requirements in the local construction market.

This paper aims to investigate how convenient a natural insulation material such as Al-Mangabi stone can play a significant role in the building sector in Jeddah. This will be achieved by comparing the common insulation materials used today in Jeddah with Al-Mangabi stone by taking the thermal conductivity values as reference. Also, this paper highlights the historical background of using Al-Mangabi.

\section{RESEARCH AIM AND OBJECTIVES}

The current research aims at quantifying the effectiveness of Al-Mangabi stone as a building material in Jeddah that can save energy in cooling down the buildings in Jeddah. This can be achieved through the following objectives:

a) Reviewing the literature and investigating the use of AlMangabi stone in building construction in Jeddah

b) Studying the physical and thermal properties of this material

c) Comparing the thermal mass capacity of this material compared to other common materials used in Jeddah.

\section{RESEARCH METHODOLOGY}

The research methodology of the current work depends on multi-methods. Qualitative and quantitative techniques are employed. Literature review and observation are used to qualitatively investigating the buildability aspects of Al- 
International Journal of Engineering Research and Technology. ISSN 0974-3154, Volume 13, Number 6 (2020), pp. 1319-1329

(C) International Research Publication House. https://dx.doi.org/10.37624/IJERT/13.6.2020.1319-1329

Mangabi stone in wall construction. While the physical and the numerical experiments are utilized to measure the thermal properties of the material.

\section{THE LITERATURE REVIEW}

At the beginning of humanity, mankind seeks to build their settlements with main principles: secured, comfortable and usable to meet with their daily needs [4]. Furthermore, the climate has been considered the main challenge due to its continuity and changes all over the year, therefore, local materials were used for the construction of the exterior facades for insulation purposes [5]. There is a lack of knowledge on the performance of the historical/traditional materials especially in the aspects of internal insulation, thermal performance, and hydrothermal behavior. The historic structures have a great thermal performance compared with the recent build techniques [6][7]. This means that traditional and historical materials can be used as an insulation tool with the appropriate retrofitting techniques to achieve a conformable thermal performance [8].

\section{IV.I The history of using AL-Mangabi stone in Jeddah}

Al-Mangabi stone was one of the main construction elements in Historic Jeddah's buildings, which used for decades until the demolition of the old city walls in 1948 [9][10]. Nowadays, there are many initiatives by the heritage activists/advocates, NGOs, and governmental bodies (SCTH, Jeddah Municipality and recently Ministry of Culture) to revive this unique material by restoring more than 50 old buildings in Historic Jeddah [11]. Most of these initiatives are mainly for touristic purposes and economic vitality [12].

Therefore, this part sheds light on the historical aspects of AlMangabi stone as one of the main architectural features in Historic Jeddah's buildings, the manufacturing of the stone, and its characteristics, functions, and names.

\section{IV.II Jeddah construction components}

"The urban and architectural character of old Jeddah reflects hundreds of years of development under different Islamic regimes, socio-economic structures, and ethnic groups, resulting in architectural styles including Persian, Mamluk, and Ottoman. This combination has created an authentic environmental style of a building known as Hejazi architecture." [13]

Old Jeddah City buildings are similar to each other with general built techniques, principles and materials, known as Hejazi architecture [14]. Fig. 1 illustrates the main Jeddah's buildings' construction components and the structure system used. It is a wall bearing structure system depending on the walls' load with horizontal or vertical wooden strips (timber imported from Java Islands, India, and Egypt) to be supported [15]. Coral blocks (Al-Mangabi stones) covered the buildings and painted by plaster for insulation and aesthetic purposes [16]. Thus, AlMangabi stones played a significant role in the Hejazi architecture due to its efficiency as a construction material and as an insulation and resistance tool, which this paper is attempting to reveal.

\section{IV.III The circle of Al-Mangabi stones from the sea into the walls}

Al-Mangabi is a coral limestone extracted from the Red Sea coast near the local well-known Al-Arbaieen Lake [17]. It has been described as "a limestone, soft and hard, porous, with rather coarse texture. The stones are more or less squared on one facing, and usually beveled roughly" [16]. The module of the stones is a regular shape of a square with no long shapes. Al-Mangabi is a local organic material available around the city of Jeddah [17]. "Al-Mangabi can be found all over the Red Sea coast", as stated by the local buyer in 2019. In addition, Historic Jeddah has many old twin cities located on the Red Sea coast (such as: Suakin in Sudan, Yanbu and Alwjah in Saudi Arabia, Massawa in Eritrea, and Hodediah in Yemen) that shared many built environments (Fig. 2 and Fig. 3) especially in using AlMangabi [18][19], which confirms the previous statement. These examples are the evidence that Al-Mangabi materials have withstood the test of time. The effectiveness and intelligence in responding to the socio-cultural and climatic context of many regions across the world for similar materials have been well demonstrated [20][21][22]. On the other hand, it is an environmentally sustainable material. Its production, installation and maintenance consume low levels of energy compared with modern construction materials and techniques; hence its low embodied energy. It is also could be reproduced and used after demolishing.

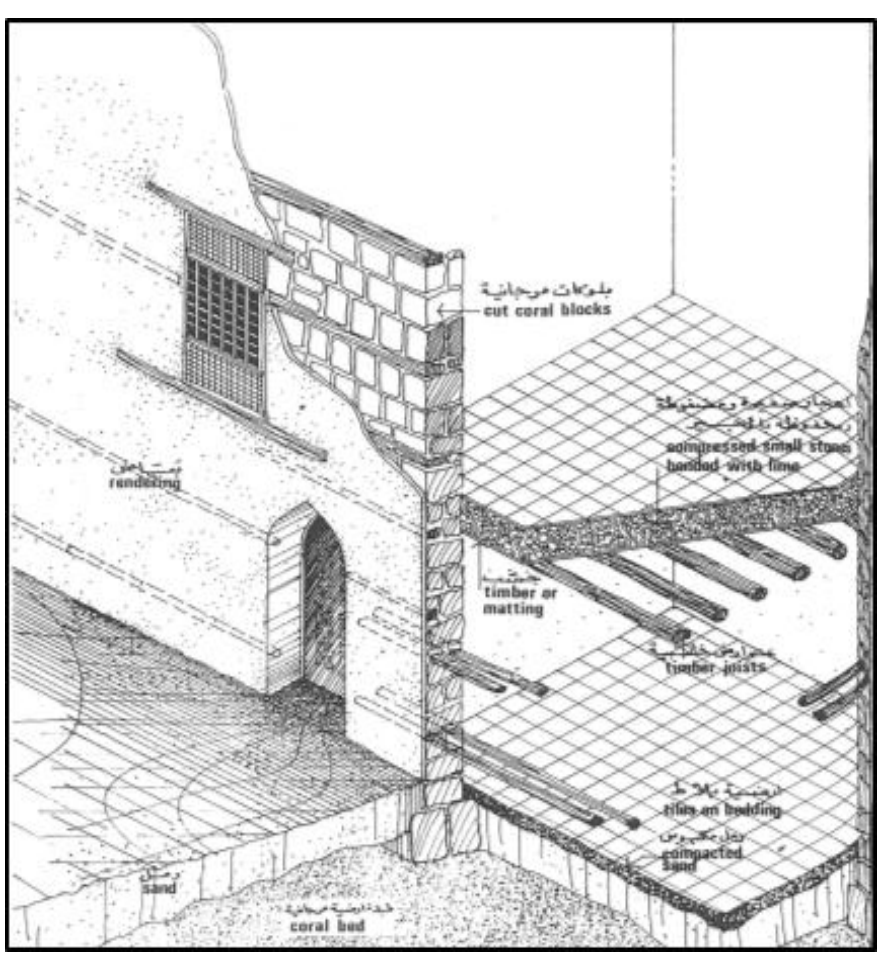

Fig 1. The main components of the traditional Hejazi Buildings (Matthew, 1981) 


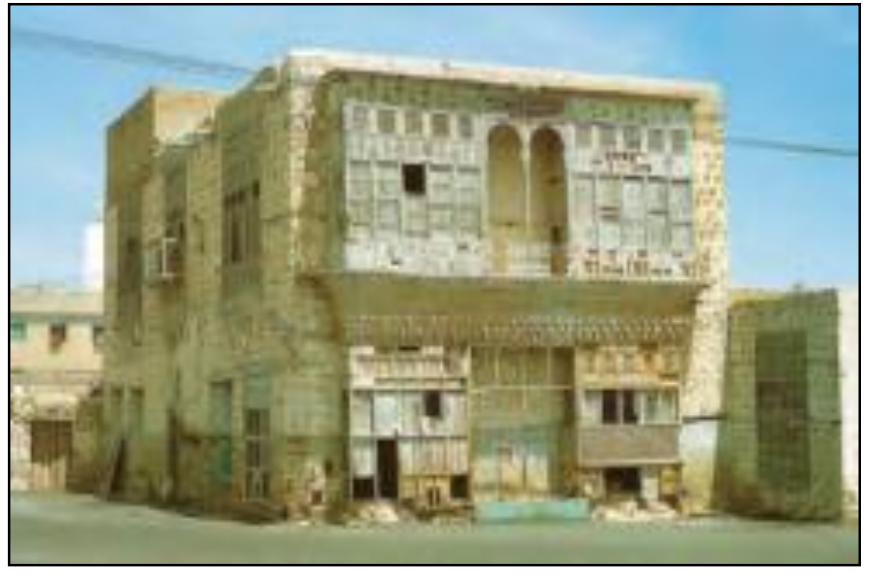

Fig 2. Old building in Yanbu in the 1990s (RC Heritage, 2009)

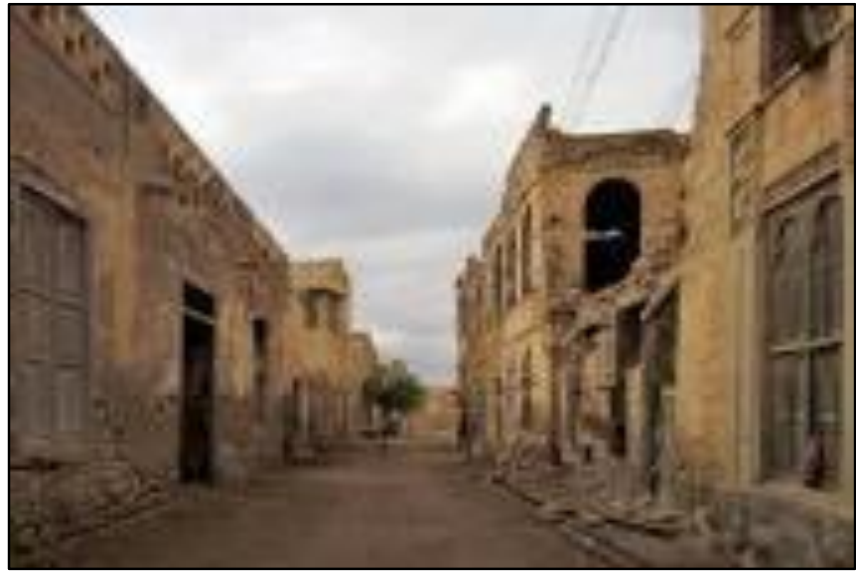

Fig 3. A photography of one street of Massawa Old City shown the limestone (Stanley, 2013)

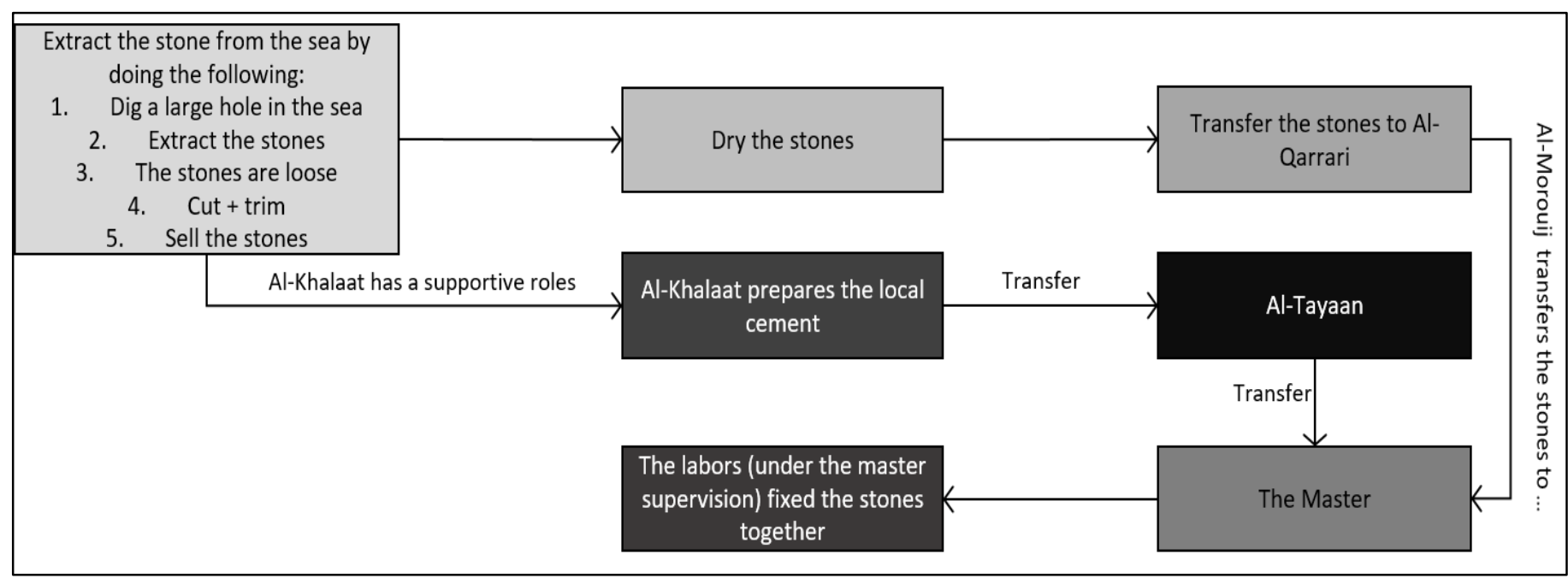

Fig 4. The procedure of extracting till fixing Al-Mangabi stones based on Abu Zaid (2012) and illustrated by the authors (2019)

A book by a local Saudi historian, has described the circle of extracting, manufacturing and fixing the Mangabi stones from the sea into the buildings' walls [17] (see Fig. 4). This circle started by digging holes in particular locations on the Red Sea shore nearby Jeddah to extract the stones (in loose condition). Next, the labors cut and trim the stones and leave it to get dry for days. The dried stones transferred by donkeys to a local manufacturer (locally known as Al-Qarrari) using his local machine (Al-Tahowna) to form the stones based on the master (Al-Muallim) requirements and instructions. Then, all the stones transferred to the master by a particular person locally known as Al-Morouij. Once the stones delivered to the master, another person (Al-Khalaat) prepared the local cement upon request to joint all stones together. Finally, the master started to build the building with his labors from 2 to 4 years.

\section{IV-IV Al-Mangabi stone: characteristics, functions and names}

The different names of Al-Mangabi stones are based on their locations and used inside and outside old Jeddah's buildings [15]. There were six types of Al-Mangabi stones with different uses, weights, and shapes (Table 1). Al-Qararri cut and trim these stones based on the Master request that mainly depended on the heat resistance, moreover, the main principle was more thickness of the stone to provide more heat absorption. For instance, the stones named Wajah Qibla and Wajah Yemen (facing the eastern and southern facades) thicker than Wajah Bahar and Wajah Sham (facing northern and western) (Fig. 5). Wajah Al-Moakh (or Wajah Al-Dayal) is usually used for the interior spaces. Finally, Al-Qanatri stones used to frame the windows and doors. 
International Journal of Engineering Research and Technology. ISSN 0974-3154, Volume 13, Number 6 (2020), pp. 1319-1329

(C) International Research Publication House. https://dx.doi.org/10.37624/IJERT/13.6.2020.1319-1329

Table 1. Names, uses and characteristics of Al-Mangabi based on Abu Zaid (2012), and reviewed, analyzed and illustrated by the authors (2019)

$\begin{array}{lll}\text { Name of Al-Mangabi } & \text { The use(s) The Characteristics }\end{array}$

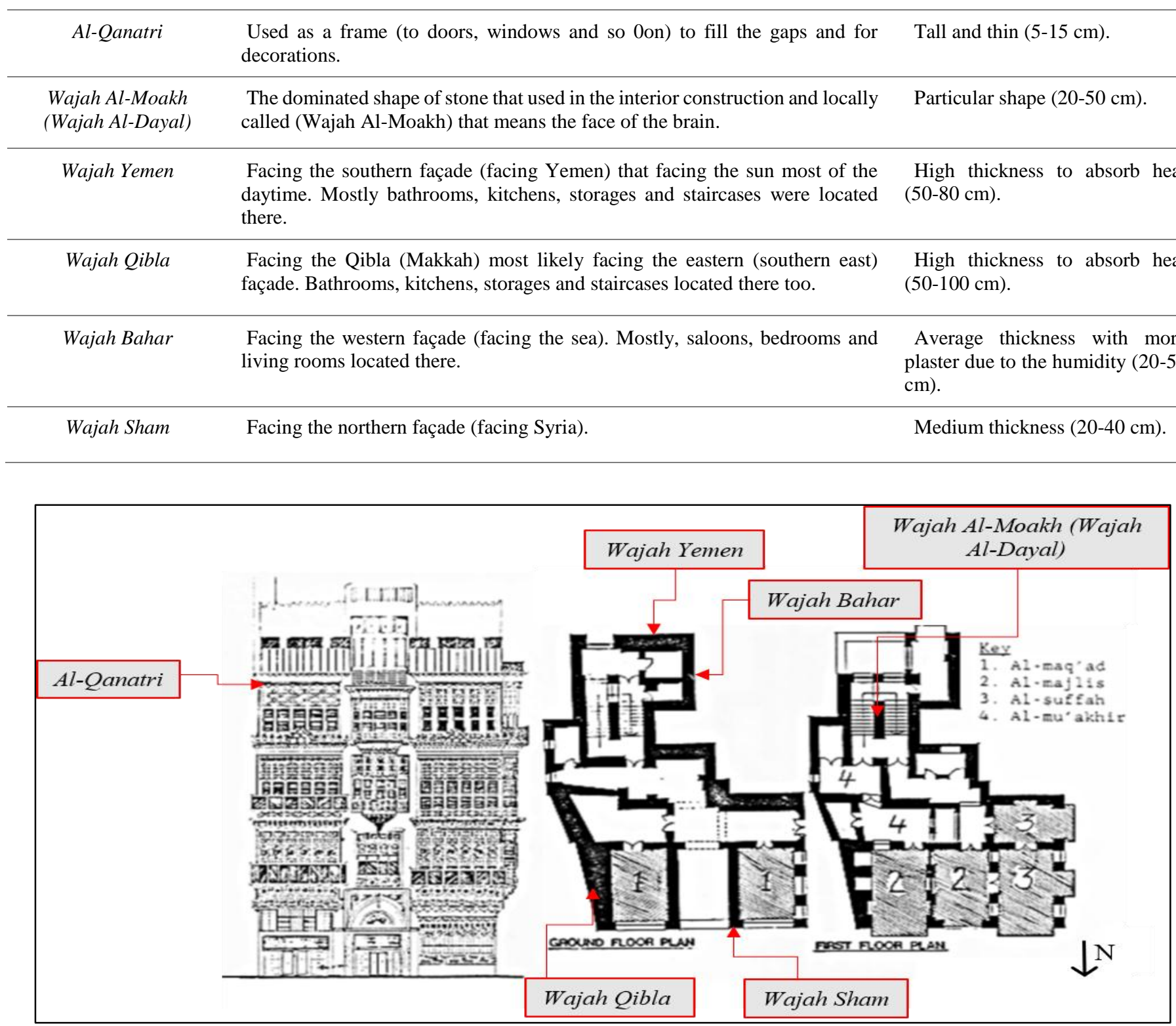

Fig 5. The location of Al-Mangabi stones based on Abu Zaid (2012), the plans by Al-lyaly (1990) and illustrated by the authors (2019)

\section{IV.V Cost and prices of Al-Mangabi stone comparing with the common insulation materials in Jeddah city}

According to a survey conducted by the authors (2019) in Jeddah's construction market presents that there are different types of construction and insulation techniques used. Firstly, the most demined materials for construction are single brick, cavity brick or the double layers of brick with insulation. Secondly, due to the extreme weather that Jeddah witnesses yearly (it reaches $55^{\circ} \mathrm{C}$ in summer), therefore, using insulation materials in the external walls are essential to reduce the heat.
Table 2 present the most common insulation materials that used in Jeddah's market today. The same table shown that most of the materials are similar to each other in the thermal properties, availability and quality, but there are more variety in the rockwool in dimensions and prices. Thus, the authors have chosen the rockwool insulation material to be compared with Al-Mangabi stone as well as the single brick that commonly used in Jeddah's buildings for insulation.

As mentioned previously, Al-Mangabi stone is a natural coral stone extracted from the seabed then dried and cut as per 
International Journal of Engineering Research and Technology. ISSN 0974-3154, Volume 13, Number 6 (2020), pp. 1319-1329

(C) International Research Publication House. https://dx.doi.org/10.37624/IJERT/13.6.2020.1319-1329

request, and the old houses of Jeddah used the stone as a building material and thermal insulation at the same time with multiple thicknesses based on the functionality (see Table 1 and Fig. 5). Today, the stone is not always available as a thermal insulation nor as a building material due to the time-consumed workmanship and lack of demand for it. Often the providers of Al-Mangabi stone in the city of Jeddah are required to provide it in small thickness $(3 \mathrm{~cm})$ for houses' and mosques' façades decoration. This led to a lack of suppliers for this type of stone, the authors discovered that only one manufacturer and few numbers of suppliers in Jeddah. Table 3 illustrates the prices of the stone according to its thicknesses and specifications as an insulation material after it was tested in SASO laboratories (later will be discussed in details).

Table 2. The properties and prices of the most common insulation materials in Jeddah City (authors, 2019)

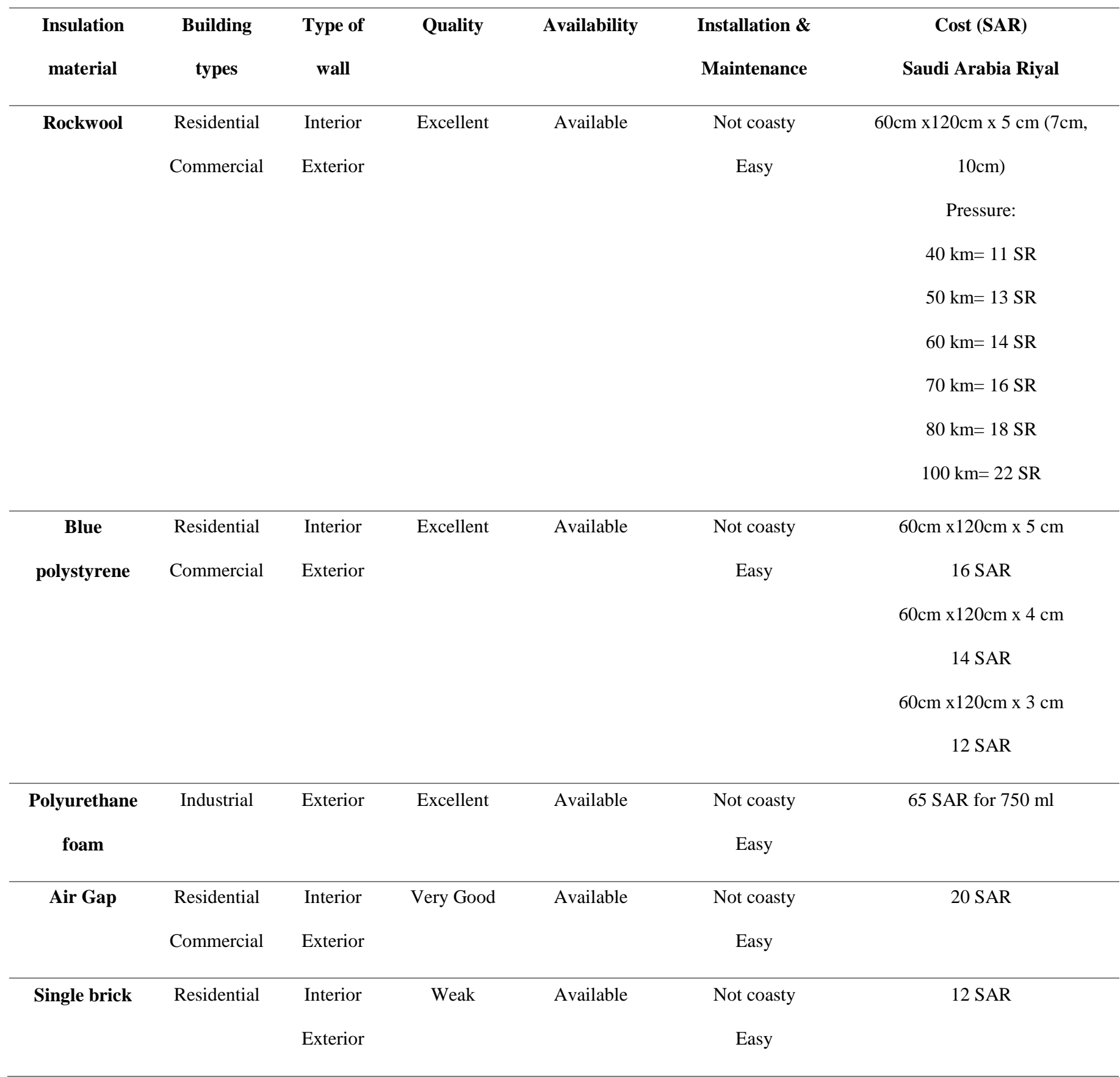


International Journal of Engineering Research and Technology. ISSN 0974-3154, Volume 13, Number 6 (2020), pp. 1319-1329

(C) International Research Publication House. https://dx.doi.org/10.37624/IJERT/13.6.2020.1319-1329

Table 3. The properties and prices of Al-Mangabi stone as insulation material (authors, 2019)

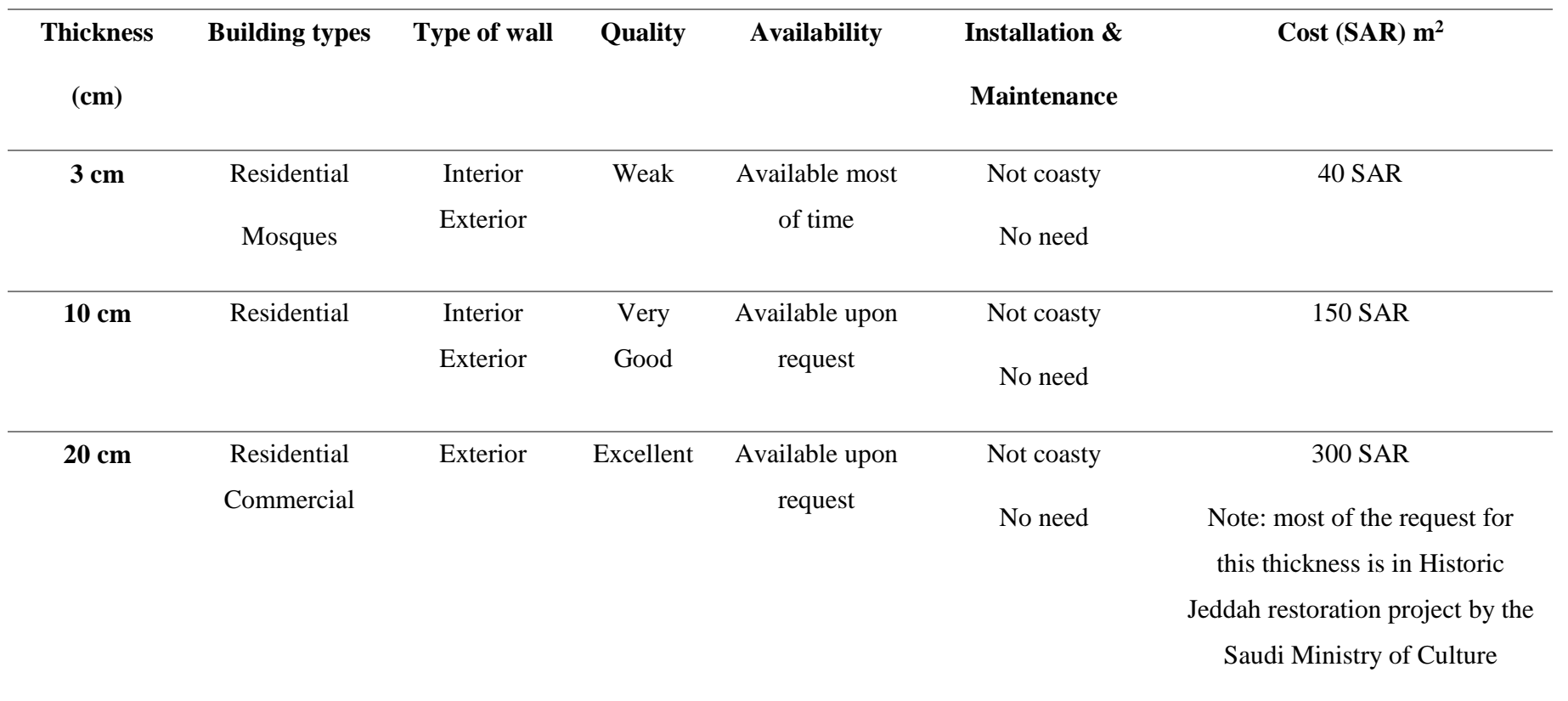

In summary, the single brick and the double layers of brick with insulation (most likely the rockwool) are the most desirable insulation materials in Jeddah city because of their quality, availability and cost. Therefore, the authors will compare these specific insulation materials with Al-Mangabi stone. Currently, Al-Mangabi stone is not considered as insulation material due to the lack of manufacturers and suppliers, and the authors claim that the lack of the public and specialist's awareness led to excluded this important material form the construction market in Jeddah.

\section{THE PHYSICAL PROPERTIES OF AL-MANGABI STONE}

Thermal conductivity measures the ease with which heat can travel through a material by conduction, conduction being the main form of heat transfer through insulation. Thermal conductivity is often termed the $\lambda$ (lambda) value. The thermal conductivity is a constant for a particular material - it is not impacted by the thickness of the material. Although when comparing different materials, products with lower thermal conductivity values are better insulators (i.e. will be better at slowing heat loss) [23][24].

Thermal conductivity is useful, but we also need to incorporate the thickness of the insulation into the calculation. The thicker the layer of insulation, the slower the rate of heat loss and also the better at retaining heat a building will be. This is where the $\mathrm{U}$-value comes in. The U-value signifies the heat lost through a given thickness of a particular material.

This allows you to directly compare types and thicknesses of insulation. $\mathrm{U}$-value $=$ Thermal conductivity / thickness (where the thickness is measured in meters). When you are comparing U-values, a lower number is better - i.e. a lower U-value signifies less heat loss through a material; therefore, it is a better insulator.
Fourier's equation was chosen to calculate the heat flow through the different wall sections [25]. It depends on the thermal conductivity of the material, its width, area, and the temperature difference between both faces of the surface:

$$
Q=\lambda \times A \times \Delta t / e
$$

(Equation 1)

Where

$Q=$ heat flow rate or simply flux rate; the total flux in unit of time through a definite surface of material or space, in $\mathrm{J} / \mathrm{s}$ units, which is the same as watts (W); in IP units, it is Btu (British thermal unit)/hr (Heat flux is the rate of heat/thermal energy transferred through a surface per unit time. Often it is expressed in terms of Joules/sec or Watts.)

$\lambda=$ thermal conductivity of the material $\left(\mathrm{W} / \mathrm{m}^{\circ} \mathrm{C}\right)$

$e=$ thickness of the material (m)

$A=$ enclosure surface or area through which heat can be transmitted; it is perpendicular to the heat flow (m2)

$\Delta t=$ temperature difference between the two faces of the surface. In the case of a building's envelope, it is the difference between the external and internal surfaces. If there is no solar radiation, it is assumed that both faces of the surface will have the same temperature as the $\operatorname{air}\left({ }^{\circ} \mathrm{C}\right)$

The conductivity of the bricks $=2.5 \mathrm{~W} / \mathrm{m}{ }^{\circ} \mathrm{C}$ and the conductivity of the insulation material is $0.038 \mathrm{~W} / \mathrm{m}{ }^{\circ} \mathrm{C}$ while the conductivity of Al-Mangabi stone is not known. Therefore, to get the actual thermal conductivity for Al-Mangabi stone, a sample of $30 \mathrm{~cm} * 30 \mathrm{~cm} * 5 \mathrm{~cm}$ was sent to the Material Laboratory at Saudi Standards (SASO), Metrology and Quality Organization in Riyadh to get the thermal properties (Fig. 6). The sample was tested using ASTM C 518 method and SASO is official laboratory for materials tests in Saudi Arabia. The results revealed that the thermal conductivity of Al-Mangabi stone is $0.64 \mathrm{~W} / \mathrm{M}^{*} \mathrm{~K}$. 
International Journal of Engineering Research and Technology. ISSN 0974-3154, Volume 13, Number 6 (2020), pp. 1319-1329

(C) International Research Publication House. https://dx.doi.org/10.37624/IJERT/13.6.2020.1319-1329
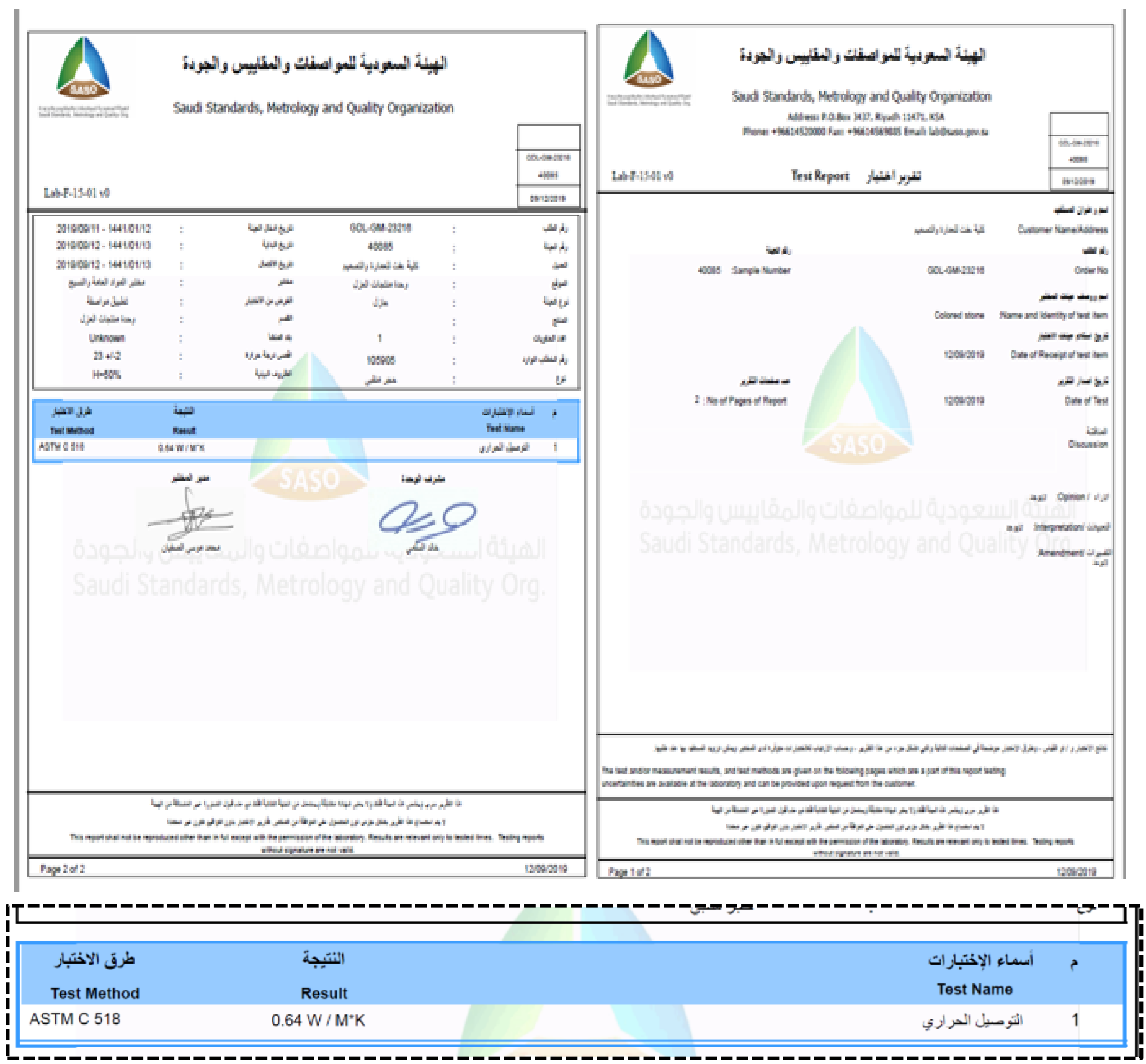

Fig 6. The thermal conductivity results from SASO (2019)

In order to test and compare the heat flow of the Al-Mangabi stone compared to other materials, a laboratory experiment was conducted. Al-Mangabi stone was imported from Jeddah shore (Fig. 7) and adjusted at the workshops of Effat University to be installed in a wooden box covered with transparent plastic with the dimensions of $56 \mathrm{~cm} \times 56 \mathrm{~cm} \times 80 \mathrm{~cm}$. the gaps between the parts of the bricks was filled These box was fabricated to represent the wall sections. Each box was provided with the followings: by pottery clay (water based) to simulate the reality (Fig. 7).

\section{a) Stopwatch}

b) Two thermometers to monitor the internal and external surface temperatures ST - 1A (in and out) c) Heat lamp with 50-watt power to heat up the external surface of the wall section.

Al-Mangabi stone with a $10 \mathrm{~cm}$ thickness was compared to two common construction materials in Jeddah with the same conditions (Fig. 7) These two different construction materials are:

a) A single layer of brick (10 cm thickness)

b) Double layer of brick with Rockwool Dual Density Board as an insulation material $(5 \mathrm{~cm}$ thickness, with a total thickness of $25 \mathrm{~cm}$ ) 


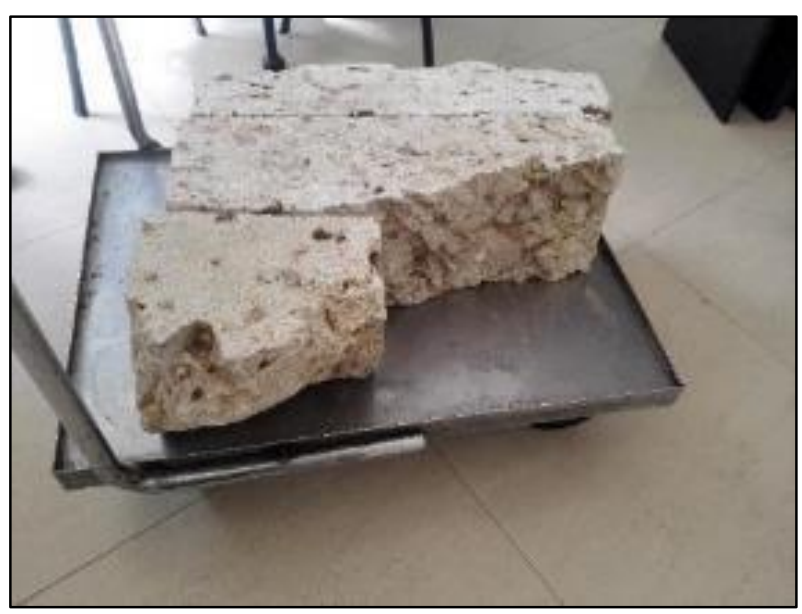

Al-Mangabi stone in its raw status

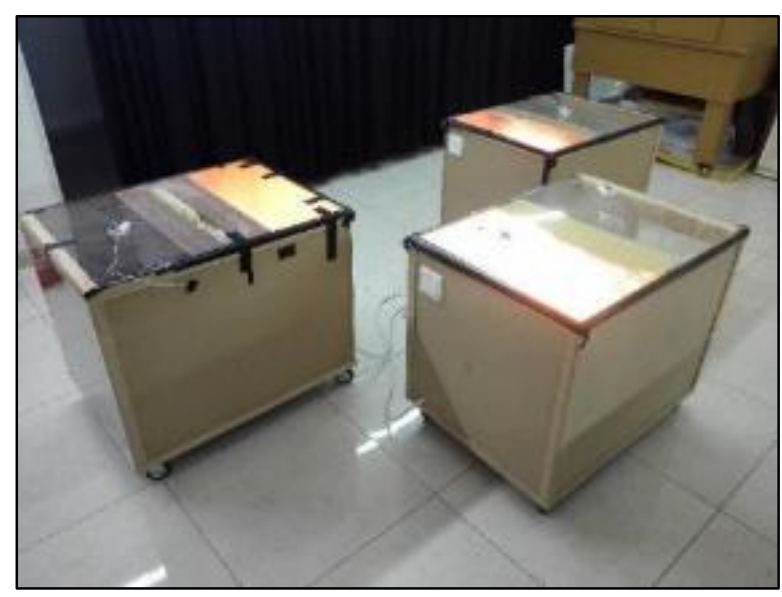

The three boxes at the Environmental Design of Buildings Lab.EDoB lab.

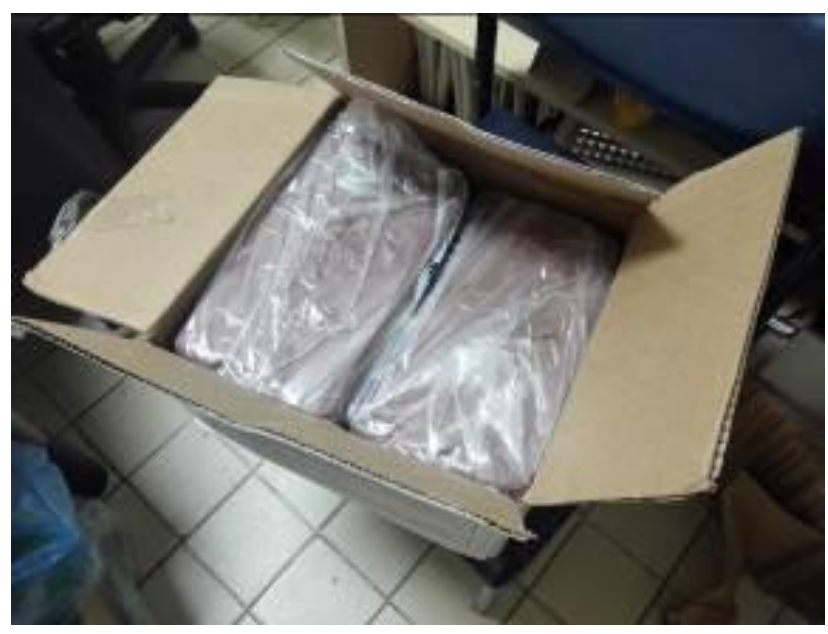

The pottery clay for the joints

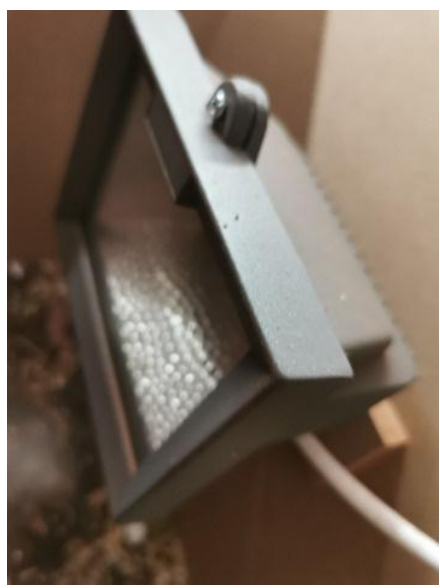

The Lamp

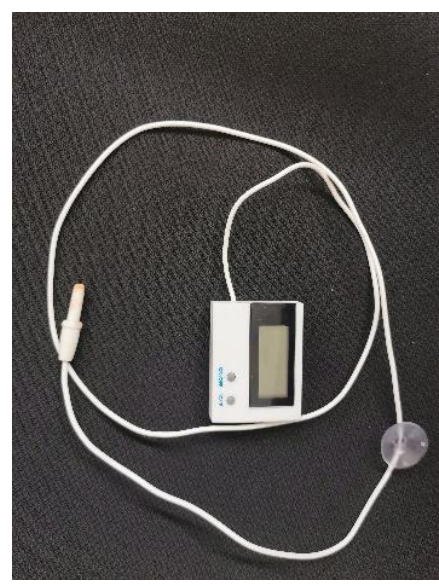

The Temperature sensor ST$1 \mathrm{~A}$

Fig 7: Components and materials of the experiment

\section{V.I Results and Discussion}

To conduct the experiment (Fig 8), the following procedures were followed:

a) The air sealed plastic box was placed over the wall section,

b) The thermal mass material was placed in the wall cavity, c) The thermometer was inserted through the hole in the top of the box and the bulb of the thermometer is attached to its surface.

d) The temperature degrees were recorded every 15 minutes in the data table during the temperature was increased gradually until we reached a steady state of temperature change [26]. 

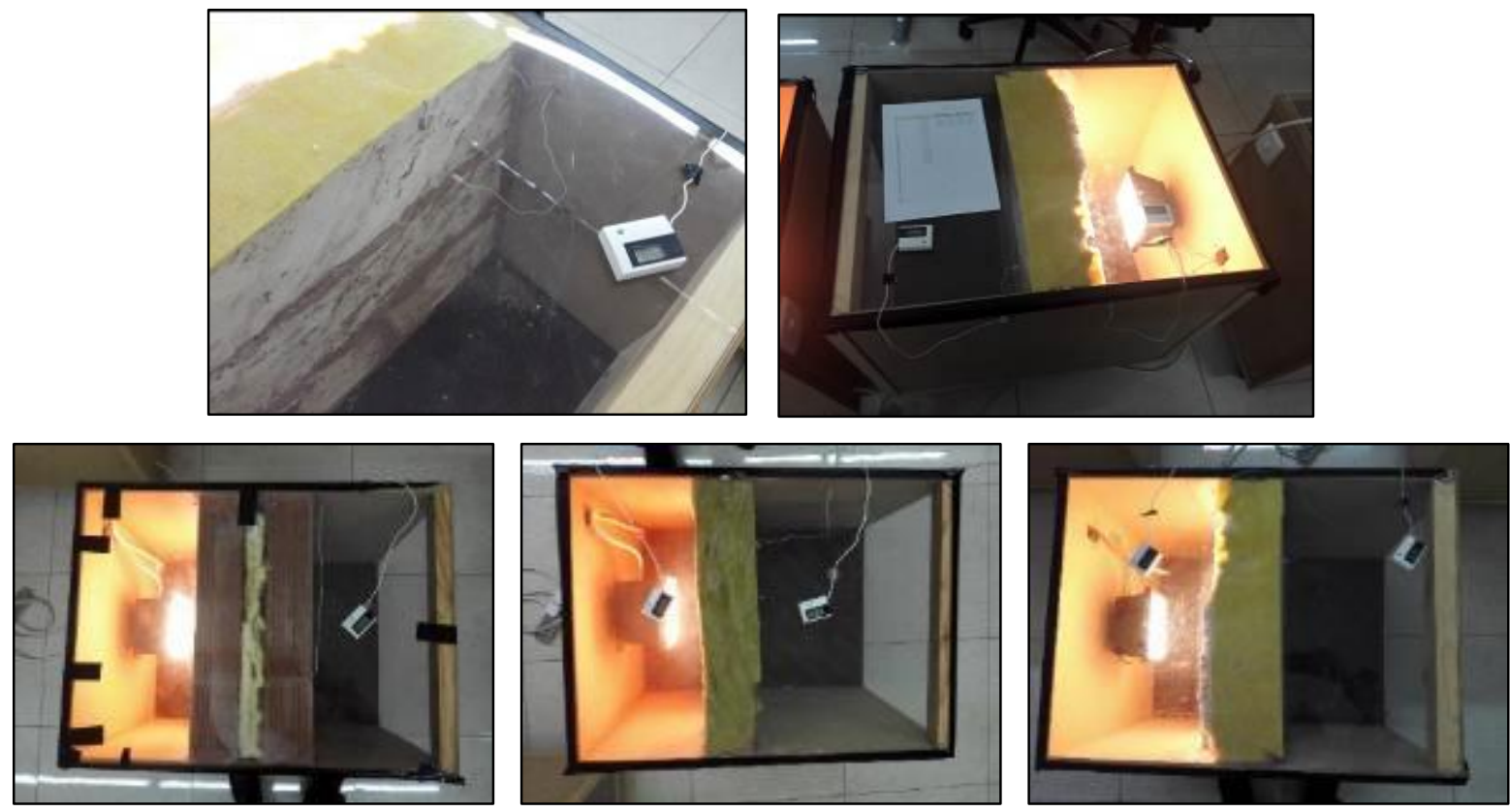

Fig 8: The three wall sections during the experiments

\section{V.II The comparison was conducted in two ways:}

a) The difference in the temperatures between the two surfaces (in/out) is visualized to show the most effective material in terms of thermal insulation,

b) The heat flow was calculated using the Fourier's equation (Equation 1).

\section{V.III Differences in surface temperatures.}

It took 11 hours inside the laboratory for the heat transfer to reach the steady-state. The experiment was started at 09:00 am and stopped at 08:00 pm. Three wall sections were exposed to the same source of heat with the same power. The external surfaces of the three case studies had the same temperature all the time. The differences were found for the temperatures of the internal surfaces which present the ability of each wall section in transferring the heat from one side to another (Fig 9). Fig. 9 is clearly shown in the chart that the single $10 \mathrm{~cm}$ brick represented the highest wall construction that allows the heat flow to transfer from the external side to the internal one. While the two-layer brick with insulation represented the lower wall construction in transferring the heat from the external surface to the internal one. It is clear from the chart (Fig 9) that the AlMangabi wall section with $10 \mathrm{~cm}$ thickness presented a very high thermal resistance compared to the brick with the same thickness.

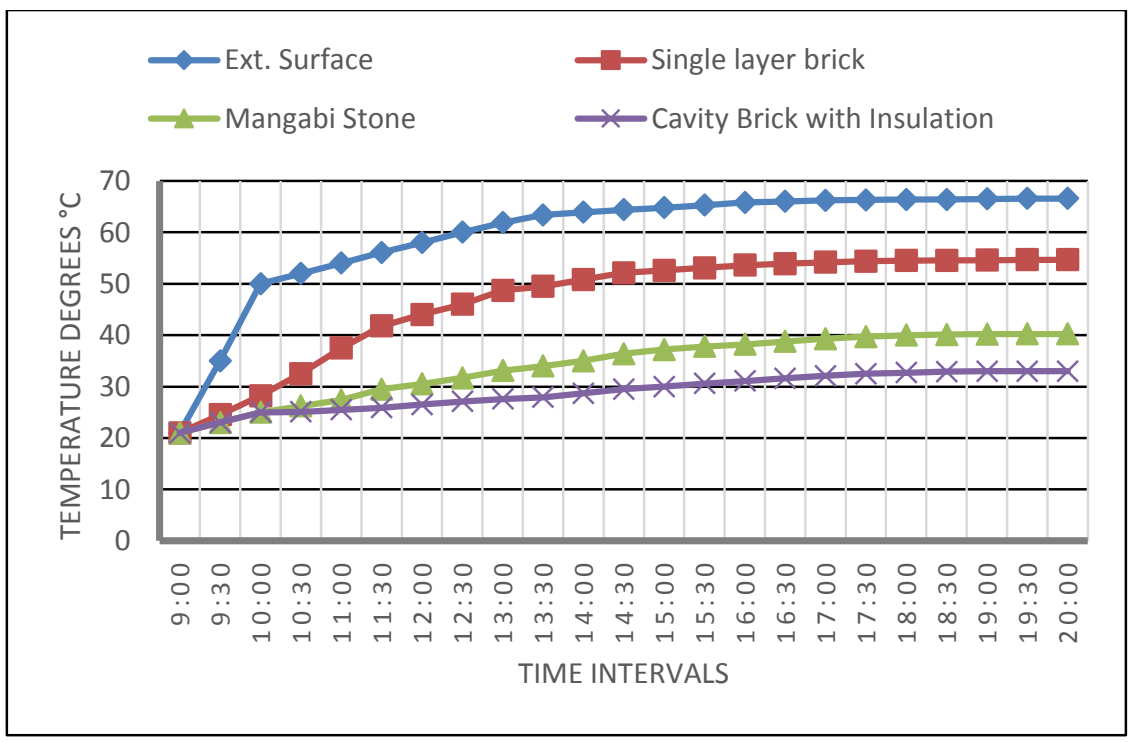

Fig 9: Surface temperatures for the tested three case studies, by the authors at EDoB Lab., Effat University 


\section{V.VI Calculating the heat flow}

In order to calculate the heat flow for each wall section, it was mandatory to calculate the thermal conductivity for AlMangabi as presented in section 5. However, Table 4 illustrates the results of how the three different materials acted with the heat flow. These results mean that every second, 129.7975 joules of heat energy are transferred through every $1 \mathrm{~m}^{\wedge} 2$ of the single-layer brick wall. While 38.6 joules of heat energy are transferred through every $1 \mathrm{~m}^{\wedge} 2$ of the Al-Mangabi wall, and 14.9 joules of heat energy are transferred through every $1 \mathrm{~m}^{\wedge} 2$ of the double-layer brick with insulation wall.

Table 4. The heat flow of three materials

\begin{tabular}{|c|c|c|c|c|c|c|}
\hline \multirow[t]{2}{*}{ Materials } & \multirow[t]{2}{*}{$\begin{array}{l}\text { Thickness } \\
\text { in } \mathbf{m}\end{array}$} & \multirow[t]{2}{*}{$\begin{array}{l}\text { Area in } \\
\text { m2 }\end{array}$} & \multicolumn{2}{|c|}{$\begin{array}{l}\text { Thermal conductivity } \\
\text { from references }\end{array}$} & \multirow{2}{*}{$\begin{array}{l}\Delta t \text { Temperature } \\
\text { gradient until the } \\
\text { steady state }\end{array}$} & \multirow{2}{*}{$\begin{array}{c}\text { Heat flow } \\
(\mathrm{J} / \mathrm{s} \text { units, which is the } \\
\text { same as watts }(\mathrm{W}) \text {; in IP } \\
\text { units, it is Btu }(\mathrm{British} \\
\text { thermal unit)/hr) } \\
\mathbf{Q}=\lambda \times \mathrm{e}-1 \times \mathbf{A} \times \Delta \mathrm{t}\end{array}$} \\
\hline & & & $\begin{array}{c}\text { Wall } \\
\text { material }\end{array}$ & $\begin{array}{l}\text { Insulation } \\
\text { material }\end{array}$ & & \\
\hline Single layer brick & 0.1 & 0.3136 & 1.23 & & 33.65 & 129.8 \\
\hline Mangabi Stone & 0.1 & 0.3136 & 0.64 & & 19.25 & 38.6 \\
\hline Cavity Brick with Insulation & 0.25 & 0.3136 & 1.23 & 0.038 & 12 & 14.9 \\
\hline
\end{tabular}

\section{CONCLUSIONS AND RECOMMENDATIONS}

The results confirmed the effectiveness of Al-Mangabi stone in terms of thermal resistance. The experiment showed that the change in the temperature of the internal surface was almost similar to the double-brick wall section with insulation. While calculating the Heat flow (Q) confirmed that only 38.6 joules of heat energy is transferred through every 1 sq. $\mathrm{m}$ of the AlMangabi wall. Therefore, this research is recommending using natural materials such as Al-Mangabi in constructing the walls of housing units in Jeddah which can provide the space with low heat flow from the external hot weather to the houses. This can save the cost of the insulation material and minimize the consumption of the required energy for cooling the buildings. Finally, the authors recommend Al-Mangabi stone to be used for at least the housing sector for less than 3 stories buildings.

\section{ACKNOWLEDGEMENTS}

This research was partially supported by Effat University in Jeddah via providing: the raw materials that used during the experiment, the Environmental Design of Buildings Laboratory (EDoB Lab.) as part of the Smart Building Research Center (SBRC) to study the thermal conductivity of the three materials, and finally the engineers who implement the experiment boxes. The authors also would like to thank the Material Laboratory at Saudi Standards (SASO) for providing the thermal properties of Al-Mangabi stones (SASO is a third party and direct request to get the test is needed). Finally, the authors would like to thank Riyadh Stones in Jeddah City (Saudi Arabia) for providing the Al-Mangabi samples for the experiments.

\section{REFERENCES}

[1] Jerman, M., Palomar, I. Koci, V \& Cerny, R., Thermal and Hygric Properties of Biomaterials Suitable for Interior Thermal Insulation Systems in Historical and Traditional Buildings, Building and Environment, Volume 154, 2019, Pages 81-88

[2] Jelle, B., Traditional, State-of-the-Art and Future Thermal Building Insulation Materials and Solutions - Properties, Requirements and Possibilities. Energy and Buildings, Volume 43, Issue 10, 2011, Pages 2549-2563

[3] Islam, S. \& Bhat, G., Environmentally-Friendly Thermal and Acoustic Insulation Materials from Recycled Textiles. Journal of Environmental Management, Volume 251, 2019, 109536

[4] Tweed, C. \& Sutherland, M., Built Cultural Heritage and Sustainable Urban Development. Landscape and Urban Planning, 2007, 83, 62-69

[5] Walker, R. \& Pavía, S., Moisture Behavior of a Historic Brick Wall Following the Application of a Range of Internal Insulations, Hoping to submit to, Building and Environment, 2015

[6] Aksoezen, M., Daniel, M., Hassler, U. \& Kohler, N., Building Age as an Indicator For Energy Consumption. Energy and Buildings. 87, 2015

[7] Hong, S.H., Gilbertson, J., Oreszczyn, T., Green, C. \& Ridley, I., A Field Study of Thermal Comfort in LowIncome Dwellings in England Before and After Energy Efficient Refurbishment, Building and Environment, 44 (6), 2009 
International Journal of Engineering Research and Technology. ISSN 0974-3154, Volume 13, Number 6 (2020), pp. 1319-1329

(C) International Research Publication House. https://dx.doi.org/10.37624/IJERT/13.6.2020.1319-1329

[8] Rhee-Duverne, S., \& Baker, P., Research into the Thermal Performance of Traditional Brick Walls, English Heritage Report, London., 2013

[9] Kaizer, T. (1984). Shelter in Saudi Arabia, Academy Editions/St. Martin's Press, London

[10] Pesce, A., Jiddah, Portrait of an Arabian City, Falcon Press, London, UK, 1974

[11] Adas, A., Wooden Bay Window (Rowshan) Conservation in Saudi-Hejazi Heritage Buildings. International Archives of the Photogrammetry, Remote Sensing and Spatial Information Sciences, Volume XL-5/W2, 2013 XXIV International CIPA Symposium, Strasbourg, France

[12] Bagader, M., The Old City Of Jeddah: From A Walled City To A Heritage Site, WIT Transactions on The Built Environment, the U.K., 2014

[13] Bagader, M., The Evolution of Built Heritage Conservation Policies in Saudi Arabia between 1970 and 2015: The Case of Historic Jeddah, a PhD thesis, The University of Manchester, the U.K., 2016

[14] Abu-Ghazzeh, T., Built Form and Religion: Underlying Structures of Jeddah Al-Qademah, TDSR, vol. 5, No. 11, pp: 49-55, London, UK, 1994

[15] Jeddah Municipality website, A special report about Historic Jeddah, 2015 [in Arabic]

[16] Ecole d'Avignon, Restoration Manual for Heritage Buildings in Historical Jeddah, a tehcinal manual submitted to Jeddah Municipality, 2013

[17] Abu-Zaid, A., The Architects in Old Jeddah, AlAmaal Al-Thagafya, 2012 [in Arabic]

[18] RC Heritage, Historic Jeddah Conservation, an official report for Jeddah Municipality, Jeddah, 2009

[19] Bianca, S., Urban Form in the Arab World: Past and Present, Zurich, 2000

[20] Mohamed, M., Traditional ways of dealing with climate in Egypt. The Seventh International Conference of Sustainable Architecture and Urban Development (SAUD 2010). S. Lehmann, H. A. Waer and J. Al-Qawasmi. Amman, Jordan, The Center for the Study of Architecture in Arab Region (CSAAR Press). 1: 247-266., 2010

[21] Mohamed, M., "Lessons from the Past to Enhance the Environmental Performance of Primary School Classrooms in Egypt." Environment and Ecology Research 2(6): 221-233., 2014

[22] Mohamed, M., A. Klingmann and H. Samir, "Examining the Thermal Performance of Vernacular Houses in Asir Region of Saudi Arabia." Alexandria Engineering Journal, 2019

[23] Xie, Z., L. Chen and F. Sun, "Constructal optimization for an insulating wall combining heat flow, strength and volume." International Communications in Heat and Mass Transfer 54: 141-147., 2014

[24] Sippawit, N. and T. Leephakpreeda, "A study of sensing heat flow through thermal walls by using thermoelectric module." Thermal Science 19(5): 1497-1505., 2015

[25] Bejan, A., Convection Heat Transfer. New York, Wiley, 1984

[26] Simpson, P., Experiment 16 - Heat Conduction. Canada, The University of Western Ontario, 2019 